\title{
A CASE OF SYSTEMIC SCLEROSIS WITH PULMONARY INVOLVEMENT AND COVID-19
}

Raíssa Dudienas Domingues Pereira ${ }^{1, \star}$, Diego de Paula Ferreira Nunes ${ }^{1}$, Caio Rustichelli Cardoso ${ }^{1}$, Vinícius Verlangieri Soubihe ${ }^{1}$, Ana Paula Toledo Del Rio ${ }^{1}$

1.Universidade Estadual de Campinas, Campinas (SP), Brazil.

*Corresponding author: ra_dudienas@hotmail.com

\section{BACKGROUND}

Systemic sclerosis is a connective tissue disease, characterized by fibrosis of several organs and tissues, with signs and symptoms varying depending on the affected structure. In the course of the disease, clinical decompensations can occur when there is exposure to some factors, such as: infections, surgical procedures or exposure to medications.

\section{CASE REPORT}

Male, 26 years old, diagnosed with systemic sclerosis since 2011, with fibrous interstitial pneumopathy as one of its manifestations. In order to prevent progression of lung disease, he has already received several therapeutic modalities, without satisfactory response. September 2019 echocardiogram showed $100 \mathrm{mmHg}$ systolic pulmonary artery pressure, showing a severe picture of pulmonary hypertension. In April 2020, home oxygen therapy was indicated; however, at the end of that month, the patient evolved with worsening of lower limb edema, increased abdominal volume and worsening of baseline dyspnea. On physical examination, in addition to the edema already reported, he had tachydyspnea, rales on the lung bases bilaterally, moderate ascites, digital ulcers and fixed Raynaud's phenomenon. In view of the clinic compatible with decompensated cor pulmonale, hospital admission was indicated. The patient evolved with significant clinical worsening, being referred to the intensive care unit (ICU). The ICU admission exams showed positive RT-PCR for coronavirus disease 2019 (COVID-19), although there were no associated flu-like symptoms. With progressive worsening of the condition, he died after approximately 1 week of hospital admission.

\section{CONCLUSION}

The COVID-19 pandemic brought new challenges in the diagnosis and management of patients who already had a severe disease. In view of a clinical decompensation in a patient with cardiopulmonary disease, it is important to carry out the differential diagnosis with this viral infection, in order to quickly start support and treatment measures. 